\title{
Aus der Redaktion
}

\section{Nachruf auf Dr. med. Liselotte Petersohn} geboren 20. Januar 1925, verstorben 25 . Juli 2016

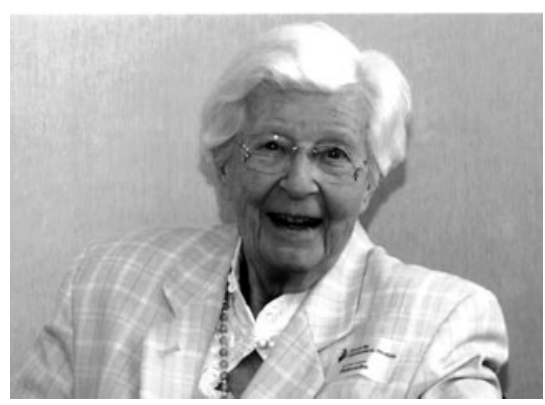

Eine große Frau der deutschen Naturheilkundeszene und speziell der chinesischen Medizin und Akupunktur hat uns verlassen.

Frau Dr. med. Liselotte Petersohn hat der Sache der chinesischen Medizin und besonders der Akupunktur in Deutschland ein besonderes Gewicht gegeben.

Dieses deutete sich schon früh an. Bereits als Zwölfjährige folgte sie in der Schule fasziniert den Ausführungen der Erdkundelehrerin über China und war endgültig begeistert, als ihr Onkel von einer damals endlos erscheinenden Reise in den Fernen Osten erzählte.

Sie studierte Medizin, und 1953, also noch nicht einmal 30 Jahre alt, erfuhr sie auf einem Kongress für Naturheilverfahren das erste Mal etwas über Akupunktur, seinerzeit von einem europäischen Wegbereiter der Ohrakupunktur, nämlich von Dr. Nogier. Sogleich begann sie als praktische Ärztin mit der Umsetzung dieser Kennnisse im Alltag.

Jeden Arzt, jeden Dozenten, der damals in der Akupunkturszene in Deutschland auftrat, lernte sie persönlich kennen und versuchte unablässig ihr Wissen zu erweitern, immer mit dem unbedingten Wunsch, ihren Patienten besser zu helfen zu können.

Zusammen mit ihrem Mann begann sie sprichwörtlich eine lange Reise in Europa zu jedem namhaften Kollegen, aber bald auch in Asien mit den Möglichkeiten, die in den 70er Jahren zugänglich waren.

Eine große innere Unruhe trieb sie. Sie war getrieben davon, die Dinge besser zu machen, weiter zu kommen, Neues zu entwickeln, andere Räume in der Medizin zu erschließen, und vor allen Dingen war sie immer von dem Wunsch getrieben, ihren Patienten zu helfen.

Krankheiten zu verstehen, zu heilen - was gab es in den 60er und 70er Jahren nicht alles neu zu entdecken? Neuraltherapie, Phytotherapie, Homöopathie und schließlich über die Akupunktur die chinesische Medizin.

Ende der 70er Jahre lernte sie unseren Lehrer Prof. Dr. Manfred Porkert kennen. Jetzt endlich hatte sie die Möglichkeit, den ersehnten "Durchblick", eine wirkliche Transparenz, eine theoretischphilosophische Basis für diese andere Medizin zu finden - so ihre eigenen Worte.

An einem August-Nachmittag 1978 lernten wir uns in München in der Dall'Armistraße im Büro von Prof. Porkert kennen. Hier gründeten wir die SMS. Mit dabei war nur noch der schon vor Jahren verstorbene Dr. Hermann Ebert. Wir waren also eine kleine Gruppe, nur zu viert.

Schon lange vorher hatte ich von Prof. Porkert in großen wohltönenden Worten von dieser eindrucksvollen Ärztin gehört, die entscheidende Impulse in der damaligen Akupunkturszene setzte. Sie wurde Vizepräsidentin unserer Gesellschaft.

Längst war Frau Dr. Petersohn aufgrund ihrer eindrucksvollen Historie zur "Grande Dame" der Akupunkturszene geworden, bei jeder Tagung anwesend, die Verbindung zu allen wichtigen Vertretern aller anderen Gesellschaften. Diese Frau wurde von allen gefragt, weil ihr Rat nicht nur fundiert und sachlich begründet war, sondern auch von einer wohltuend verbindlichen Art, und immer wieder baute sie Brücken und brachte zerstrittene Gruppierungen zusammen, pflegte alte Freundschaften.

Es kamen jetzt Jahrzehnte mit großer Schaffenskraft. Sie war dabei, als sich in Deutschland, gerade auch mit der SMS, die chinesische Medizin entwickelte.

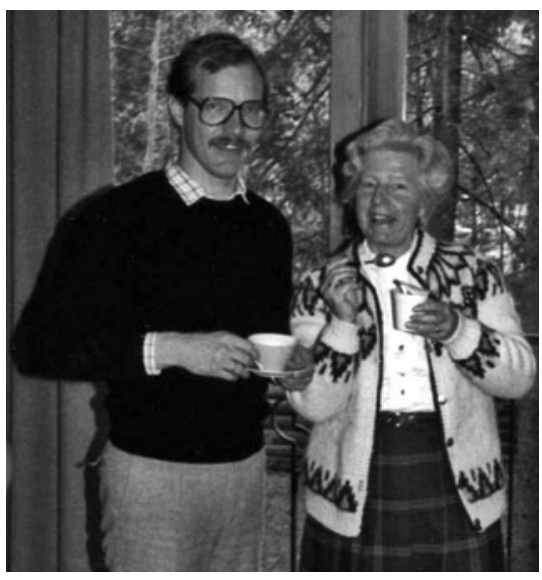

Carl-Hermann Hempen und Frau Liselotte (Fotos: privat)

Denn sie schöpfte eben aus dieser Erfahrung, die sie über 50 Jahre erworben hatte, weil sie bereits 1952 mit ihrem Mann als erste gemeinsame Praxis ein „Behandlungsinstitut für naturgemäße Heilweisen“ gegründet hatte. Damals hat niemand über derartige Heilverfahren gesprochen, aber das Ehepaar Petersohn bezog frühzeitig Therapieverfahren wie die Kneipp'sche Hydrotherapie, die Homöopathie, die Chirotherapie, das Autogene Training und dann schließlich die Akupunktur bis hin zur Elektroakupunktur nach Voll in den Behandlungsplan mit ein.

Nimmermüde ging sie der Arbeit nach. Mit Elan, liebevollem menschlichem Einfühlungsvermögen, aber gleichzeitig beeindruckender Tatkraft erschloss sich Liselotte Petersohn gemeinsam mit ihrem Mann viele neue Behandlungsweisen.

Sie war eine Vielgefragte. Auch mein Lehrer Prof. Porkert konsultierte sie regelmäßig, da ihr Rat besonders wertvoll war. Und es ging nicht nur um das Wissen. Sie war so willensstark, zielgerichtet, immer voller Einsatz für die Sache, aber gleichzeitig liebevoll, bescheiden, zurückhaltend und außerordentlich hilfsbereit. Jede noch so kleine Bitte konnte sie sofort von den Lippen ablesen. Alles war ihr selbstverständlich. Immer da sein für die anderen, für die Patienten, immer helfen.

Dieses ist es, was als ewiges Gedenken bleibt. Wir danken Liselotte Petersohn, dass sie uns so lange, so hilfreich begleitet hat. In diesem Sinne werden wir sie immer bei uns wissen.

Carl-Hermann Hempen, München 